\title{
EM TORNO DA LETRA: LINGUAGEM, ENSINO E SUBJETIVIDADE*
}

\author{
Cristóvão Giovani Burgarelli, \\ da Universidade Federal de Goiás
}

\begin{abstract}
Resumo: Pretendo, com este artigo, indagar, mais uma vez, dando sequência a pesquisas anteriores dentro da temática linguagem, psicanálise e educação, sobre o que está em jogo quando se propõe a pensar a entrada da criança na linguagem. Considerando mais especificamente o processo escolar de alfabetização, tentarei discutir a função do texto bem como o jogo desejante que sua materialidade poderá constituir, o qual se aproxima do processo inconsciente em que se pode situar a subjetividade. Primeiramente vou considerar algumas questões introduzidas por Borges (2006) sobre o processo de alfabetização e o papel do texto. Num segundo momento, procurarei uma maior implicação com os conceitos fundamentais da psicanálise, objetivando poder discutir a questão da subjetividade. Por fim, pretendo tomar os três itens do título, linguagem, ensino e subjetividade, em seu enodamento irredutível, o que me permitirá discutir os três elementos principais envolvidos na trama educativa, criança, professor e texto.

Palavras-chave: Papel do texto. Escrita. Corpolinguagem.
\end{abstract}

\section{O PROCESSO DE ALFABETIZAÇÃO E O PAPEL DO TEXTO}

Como resultado de sua tese de doutorado, defendida em 1995, Borges (2006), contrapondo-se à visão que considera a escrita como representação da linguagem oral e partindo de dados coletados numa experiência de alfabetização, discutiu as relações oralidade/escrita/língua. Recorreu especialmente às noções de significante, metáfora e metonímia para analisar esses dados e chegou ao entendimento de que a escrita que a criança produz em seu processo de alfabetização, mesmo nas formas gráficas

\footnotetext{
* Artigo recebido em 15/10/2011 e aprovado em 3/12/2011.
} 
indeterminadas e heterogêneas, é constituída pelo Outro, representado, segundo ela, principalmente pelos discursos e textos que circulam na sala de aula. Esse conceito de Outro, subvertido com relação aos referenciais interacionistas, percorre toda sua tese, referindo-se principalmente a uma tensão constante entre estas duas noções: o funcionamento linguísticodiscursivo e o impossível de ser simbolizado pela linguagem.

Enquanto as abordagens interacionistas vigentes nos estudos sobre alfabetização e aquisição de linguagem procuravam interpretar essa passagem da garatuja à escrita constituída recorrendo a estudos sobre a relação sujeito/objeto, sujeito/outro, sujeito/contexto social, ou sujeito/ funções sociais e comunicativas da linguagem, essa autora privilegiou a relação sujeito/língua, buscando discutir e explicar essa captura da criança pela linguagem. Objetivou-se, portanto, responder, pelo menos em parte, mas com categorias de análise pertinentes à Linguística, como, no processo de aquisição da fala e da escrita, os elementos formais passam a ser categorizados e regidos por leis sintáticas, fonológicas, morfológicas, semânticas e gráficas. Sua questão não era mais, portanto, sobre como a criança, com sua cognição, (re)construía a língua, mas sim como a língua, em seu funcionamento, marcava a criança e a tornava um sujeito singular.

Um ponto de diferença que se realça nessa abordagem é, sem dúvida, o conceito saussureano de língua, pois o que se põe em pauta são as consequências do fato de que tanto os componentes fônicos quanto os gráficos constituem unidades diferenciais e, portanto, só assumem um lugar na cadeia como significantes. Em vez da noção psicológica que comporta o termo representação e em torno da qual giram as noções cruciais vigentes nas atuais teorias da aquisição da linguagem, abre-se um novo campo de investigação pela via dos processos metafóricos e metonímicos. Um retorno a Saussure com a contribuição de Jakobson (1988) e Lacan (1998).

Fugindo do entendimento de que a linguagem oral seja o referente para a escrita, que seria a referência, sua análise centrou-se no fato de que tanto a oralidade quanto a escrita são formas de linguagem que, embora diferindo, são mutuamente constitutivas pelo processo metaforonímico, ou seja, pelo, no funcionamento da linguagem. Borges (2006), em vez de recorrer à noção de professor como valorizador da criança e do contexto, preocupouse com um funcionamento, com uma estrutura, isto é, com um terceiro, que convoca e captura tanto um quanto outro elemento da suposta relação dual pensada anteriormente.

Para Borges, as formas "ilegíveis" ou "incompreensíveis" grafadas pelos alunos alfabetizandos não são da ordem da pré-escrita (ou de qualquer outra 
noção semelhante), pois são determinadas pela lógica do significante, portanto vindas do campo do Outro, marcando o sujeito desde o início. Ela nos diz: 1) "há, nessas escritas iniciais, um jogo de estruturas complexas", no qual "as letras se aglutinam em blocos que se repetem, embora com variações"; 2) "esses blocos organizam-se como que em sintagmas com ares de frases"; 3 "esses sintagmas, por sua vez, estão dispostos em estruturas paralelísticas" (BORGES, 2006, p. 129). Trata-se do jogo da língua, que articula repetição e alteridade e constitui o que se realiza tanto na oralidade quanto na escrita.

Com base na unilateralidade da banda de Moebius, ${ }^{1}$ a elaboração de Borges desloca-se da posição dicotômica entre oral e escrito, buscando sustentar que, para ler e escrever, é necessário recalcar as imagens e os sons. Segundo ela, para que o ler tenha lugar, é preciso o apagamento das substâncias imaginárias das unidades gráficas e sonoras de qualquer extensão, para que, em retorno, elas possam comparecer como traços, como efeito de um sistema que não é, ele mesmo, presença, e sim diferência. ${ }^{2}$ Os textos das crianças são, portanto, marcas de uma filiação singular ao funcionamento da língua, que, como uma tesoura, recorta, numa bateria de significantes, o jogo de combinatórias a ser manifesto (na superfície do papel, por exemplo); um jogo em cujas brechas um sujeito advém.

Mais à frente, no item dois, pretendo articular esse passo de Borges esse da ausência e da diferença, não o da consciência e da substância - com o conceito de pulsão, tentando pensar que a distribuição dos investimentos significantes instaura no sujeito a falta na qual se situa o inconsciente; ou seja, que algo no aparelho do corpo é estruturado dessa mesma maneira: numa unidade topológica das hiâncias, que se põem a jogar.

Por agora, mais um ponto importante na tentativa de explicitar por que me interessa em muito essa elaboração sobre a lógica do significante: o que costumava ser considerado pelas pesquisas sobre a aquisição da linguagem como resto no processo foi tomado, então, como objeto de tese - o insólito jogo das letras, o quebra-cabeça da escrita. Numa perspectiva freudiana, Borges pensou o estatuto simbólico dos traços mnêmicos e discutiu a passagem de um aparelho psíquico, mental, a um aparelho de linguagem. Em outras palavras, tentou cavar algumas consequências do conceito de representação, conforme Freud a trabalha em sua metapsicologia. ${ }^{3}$ Nenhuma anterioridade com relação à linguagem. Foi a partir daí que ela pôde tratar a aquisição da escrita como um processo de subjetivação, bem como estudar os efeitos do trabalho do significante.

Alçando, portanto, os grafismos iniciais da criança à posição de escrita, ou seja, à condição de uma materialidade cuja constituição se dá pelo 
jogo das relações, e em ausência, Borges pôde perguntar-se pelo sujeito do inconsciente, tal como subvertido pela psicanálise. Mais do que isso, pôde incitar novas pesquisas sobre várias questões, a partir de agora, insistentes quando se propõe a pensar a relação professor/texto/aluno, ou ainda, o estatuto da escrita para essa situação específica e para diversas outras.

Algumas dessas questões interessam, particularmente, à continuidade deste texto. Na escola, numa sala de alfabetização, o que faz o professor, o que faz o texto e o que faz a criança? O que está implicado na passagem de não leitor a leitor? Por que a partir desse momento a criança pode dizer "eu sei escrever", e não apenas desenhar? Nessa articulação sujeito-linguagem, como pensar a dimensão do desejo? E por fim: qual a contribuição dessa teoria do significante para se pensar a constituição do corpo e a configuração de seu gozo?

\section{CORPO E ESCRITA}

Lacan (1961-1962), em seu seminário "A identificação", diferencia a função de idealização que assume, na filosofia, a noção de sujeito da função de identificação ao significante, que é a sua tônica. Recorrendo ao "penso, logo existo", de Descartes, ele propõe que essa máxima seja tomada numa subversão radical. Conforme comenta: se o"penso"for considerado como"sou um ser pensante", isso resultará na seguinte sentença tautológica"sou um ser essencial ao ser"; já por outro lado, se se sustenta o paradoxo aí implicado, contrapondo-se ao preconceito que, segundo ele, suporta o desenvolvimento da filosofia, tem-se aí um limite a ser superado, uma dobradiça para a possibilidade teórica de um arcabouço sobre o inconsciente.

O paradoxo de que se trata, para Lacan, é que, por um lado, confirmase a autonomia do sujeito e, por outro, a sua ignorância, pois esse ser engendra justamente aquilo que ele desconhece e, por isso, só poderá ser cúmplice, conscius, desse saber tardiamente (après-coup). Um paradoxo que constitui o próprio campo do inconsciente, impossível de se formalizar, visto que, dessa permanência do sujeito, só é possível mostrar a referência, e não a presença. Quando se toma, por exemplo, qualquer elemento ou objeto como um, podendo incluí-lo numa série ou numa contagem, não se obtém nada mais do que seu traço distintivo, por mais que o apagamento desse traço o faça assemelhar-se o mais possível a um outro, ou seja, ao ser contado, o eterno retorno desse traço escapa à identidade.

Lacan avança com essa discussão detendo-se na questão do nome próprio, que tem a ver, segundo ele, não com um "prestar atenção" a um material sonoro (pensar), mas sim a uma "emissão nomeadora" (nommante), 
ou seja, a algo que, em sua estrutura radical, é da ordem da letra. Ele está ligado, portanto, não ao som, mas à escrita. Para explicar em que consiste a natureza da letra, Lacan faz referência aos ideogramas, que, segundo ele, tornam-se ideogramas exatamente quando perdem seu caráter de imagem. Trata-se de um figurativo apagado, repelido, do qual permanece algo da ordem do traço unário, que funciona como distintivo e que permite servirse, simultaneamente, ao uso ideográfico e fonético do mesmo material. Nas palavras de Lacan: "como bagagem [a escrita] esperava para ser fonetizada, e é na medida em que ela é vocalizada, fonetizada como outros objetos, que a escrita aprende, se posso dizer, a funcionar como escrita" (lição de 20/12/1961).

Dessa forma, Lacan reforça seu argumento de que o nome próprio se encontra ligado a esse traço de escrita. Assim se inverte a elaboração de que um "prestar atenção" ao som levaria ao que está em jogo no nome; ao contrário, é alguma coisa que já é escrita que passa a poder servir, nesse nome, como suporte do som. Allouch (1995) comenta que essa conjetura de Lacan sobre a origem da escrita pode ser entendida como a via suscetível de retomar o inconsciente freudiano com suas consequências. Pensando-o "estruturado como uma linguagem", torna-se possível livrá-lo de interpretações reducionistas e coibir o incessante retorno ao idealismo, pois, ao situar historicamente o nascimento do significante e o advento da escrita, Lacan está propondo que o signo seja lido como um significante, ou seja, que se faça uma leitura do lado de fora do que aparece como ambiente, pelo fato da presença da linguagem no real. Nessa leitura, o material que já se encontrava ali sofre uma escansão, e isso permite que o sujeito se engane tomando o um pelo diferente; o fora pelo dentro.

Em síntese, o fato de Lacan colocar, por essa via, o inconsciente numa relação com o real implica a passagem de uma concepção metafísica de linguagem, de discurso, a uma outra, materialista, em que se vê implicado o corpo falante, que é justamente o que ficou de fora, até então, de toda a estruturação do pensamento científico. Em outras palavras: devido à identificação a um significante, o sujeito é uma hipótese, em cuja base se situa o engano proveniente de seu não-saber sobre sua origem; e o inconsciente, porque suporta esse engano, faz com que se escrevam as condições de $g o z o^{4}$ desse corpo falante, mas, ao mesmo tempo, porque é num real que se funda, permite contar os resíduos desse gozo.

Antes de dar continuidade ao que tento articular, é preciso desenvolver aqui, pelo menos em parte, essa noção de real que Lacan introduz em sua obra, principalmente a partir do seminário sobre a ética, realizado em 1959-1960. Uma dobradiça possível para situar teoricamente essa noção 
é considerar, com Lacan, que há algo no real que padece de significante e, devido a isso, como ele nos diz na página 91 desse mesmo seminário, "o significante é, no homem, desde logo entronizado no nível inconsciente, misturando suas referências com as possibilidades de orientação que seu funcionamento de organismo natural de ser vivo lhe confere".

Aquele que fala habita a linguagem, que, tendo incidido sobre o organismo e evocado o corpo, agora o escande, paradoxal e ininterruptamente, pelo saber significante e pelo gozo. Enquanto, por um lado, o significante faz semblante, e por isso a escrita se apresenta como se não tivesse nada a ver com o corpo que a empunha, por outro lado, para que um sujeito possa dela "fazer uso", faz-se necessário que se tenha completado para ele o enlaçamento pulsional. É nesse campo, assim logicamente estruturado, que se encontra o sujeito; um campo cingido por uma barreira, por uma inacessibilidade e que, por isso, não cessa de produzir operações cujos restos também se fazem notar.

Não posso, neste texto, desenvolver passo a passo esse arcabouço, no entanto faz-se necessário dizer algumas palavras sobre as articulações entre significante e desejo e entre letra e pulsão.

Quando tentei falar, desde o primeiro item, de uma lógica que não nos permite pensar numa ordem simbólica fechada, e sim numa que não pode evitar a produção de resíduos, de fendas, diante dos quais o sujeito comparece como incógnita, de certo modo eu estava trazendo também a noção de sujeito do desejo. Dizendo de outra forma: porque linguagem é isso que é, o que seria da ordem de uma necessidade (orgânica, por exemplo) vai ser tomado como uma demanda do Outro (da mãe, por exemplo, que nomeia cada uma dessas "necessidades"), e, mais um passo à frente, essa demanda deverá ser atravessada e tomada como desejo de um sujeito (a criança terá incorporado o corte próprio à linguagem e agora poderá sentir no corpo seus efeitos).

Agora, neste segundo item, o que estou tentando reforçar é que o corpo falante se depara com os restos inassimiláveis da operação simbólica, e, como se pode observar, isso ultrapassa a dimensão significante. Porque tal operação deixa sempre sobrar a verdade de um ponto opaco de real, ela traz a memória de um gozo perdido, inaugura a dinâmica do inconsciente e representa o sujeito no seu nascedouro. Entramos então no terreno da letra e da pulsão. Em síntese: com o primeiro passo teórico proposto por este texto é possível dizer que há desejo indeterminado na linguagem; já com o segundo, delineia-se uma abordagem possível à questão sobre o que é o corpo, isto é, sobre o mistério ou o escândalo do corpo falante. 
O simbólico estrutura-se, portanto, a partir do suporte relacional que a letra introduz entre corpo e encadeamento de significantes. Em seu processo de constituição, o sujeito é convocado a inverter o que seria da ordem de uma necessidade orgânica para um funcionamento gramatical. E somente depois dessa inversão, ele pode completar o primeiro ciclo das pulsões, passando-se de passivo a ativo e podendo, convencionalmente, fazer uso da escrita. Em outras palavras: devido à dimensão irredutível da letra, que pode ser entendida por um lado como a estrutura localizada do significante e, por outro, como algo que, irrompendo do real, assume o estatuto de borda ao gozo expulso do campo simbólico, a escrita pode ser entendida como uma instância de repetição do resto que foi exilado do campo do saber, permitindo, assim, uma amarração entre significante e real. Em síntese, pode-se ver nas letras escritas um procedimento homólogo ao do complexo de castração. As bordas dessas letras são como as bordas do corpo, que precisam ser erotizadas para que passem a formar uma cadeia.

Desde a forçagem que a fala da mãe promove para que se dê a entrada da criança num funcionamento linguístico, nisso que se pode chamar de uma "fonação com regras" (Bergès, 1994, p. 7), observa-se que a linguagem, diferentemente do barulho, tem que ser escutada na sua organização muito particular, segundo as leis de uma gramática. A letra que se escreve aí porta a lei, o que permitirá novos engendramentos, entre eles a causação do desejo, implicado na divisão do sujeito, isto é, na borda entre a estrutura significante e a dimensão do real, na qual se encontra o corpo. Porque o gozo do significante é tomado como gozo do corpo e vice-versa, o sujeito empenha-se a elaborar algum saber, isto é, paga com a carne os custos da elaboração de um saber.

Costa (2001) também se dedica a essa elaboração em que a escrita é pensada como estreitamente ligada ao corpo. Segundo ela, porque a escrita transporta detritos, restos não assimiláveis, pode-se entender que a letra faz borda nesse corpo, dando-lhe um tema, um argumento, e determinando sua fisiologia. Ela é um resultante relacional, o precipitado do enigma inassimilável que representa o Outro. Pensando a entrada da criança na linguagem, Costa diz que a letra se produz num corpo que não é nem da criança nem da mãe, ou seja, ela constrói uma fronteira que organiza esses indivíduos mãe/criança. Já quanto à aquisição da escrita, essa autora contribui para que se afirme que a relação da criança com a língua materna é a condição de um registro que se poderia denominar corpolinguagem, ou seja, a condição da memória do recalcado, isto é, a memória do Outro primordial. Segundo ela, a escrita busca dar conta daquele traço que diz respeito ao ato originário, impossível de se escrever. ${ }^{5}$ 
Ainda nessa relação criança/linguagem, um ponto também importante de se pensar são as brincadeiras, ou seja, esse modo bastante peculiar de forçagem, de implicação do infans com o jogo da linguagem. $O$ lúdico, que comparece no brincar com o corpo, bem como com as palavras e com os objetos-brinquedos, traz em seu cerne as referências gramaticais, ou seja, fundamenta-se no artifício próprio ao jogo da presença sob o fundo da ausência e vice-versa. Ele pode ser entendido, então, como um ponto de vinculação entre a estrutura da linguagem (a sua gramática) e os atos empreendidos pelo sujeito, com o seu corpo. De certa forma, trata-se da mesma forçagem que se põe em jogo no movimento de entrada da criança na escrita, no período de alfabetização, pois, à medida que a leitura e a escrita vão-se tornando correntes, o corpo da criança torna-se capaz de libertar-se - agora de um modo muito particular - do corpo da mãe.

Lacan (1995, p. 204) diz isso da seguinte maneira: na borda do Édipo, ao assumir o falo como significante, a criança se confronta com a ordem simbólica das trocas, cujo pivô é a função paterna. Uma função terceira que se põe entre mãe e filho convocando um processo de elaboração por parte do sujeito. Sendo o pai um significante que surge no lugar de outro significante, abre-se a via da metáfora, pela qual o objeto de desejo é convocado a deslocarse, isto é, primeiramente troca-se a mãe pelo objeto do desejo da mãe, o falo, e abre-se, a partir daí, a via das sucessivas substituições.

A recente tese de doutorado de Carvalho (2011), denominada Escrita, repetição e elaboração, retorna às principais questões do projeto de pesquisa iniciado na Faculdade de Educação da UFG, em 1995, como consequência do trabalho de Borges. Ela busca avançar, sobretudo, com o entendimento de que tanto a escrita da criança quanto as suas brincadeiras constituem o processo de repetição-elaboração, constitutivo da subjetividade. Constituise, portanto, num trabalho fundamental com que a criança se envolve, considerado pela autora como condição para que a criança ponha a se haver com a impossibilidade de representar o enigma de sua sexualidade e passe a alguma elaboração. Sua possibilidade de criação é entendida como forma de situar-se singularmente no mundo.

Retomando os dados coletados em projetos anteriores e relendo elaborações pontuais da pesquisa - principalmente a tese de Borges (defendida em 1995 e publicada como livro em 2006) e a de Burgarelli (defendida em 2003 e publicada como livro em 2005) -, Carvalho (2011) discute a entrada da criança na escrita entendendo-a como uma resposta (advinda do próprio processo de causação psíquica) capaz de bordear aquilo que ela não pode saber sobre a sua origem enquanto sujeito desejante. Segundo Carvalho, 
dos textos iniciais das crianças vazam elementos que apontam para esse impossível de ser escrito, ou seja, para o real, fundamentalmente relacionado à sexualidade e ao inconsciente (p. 14).

Quanto às nossas pesquisas, portanto, desde o Projeto escrita, em 1996, até o Em torno da letra, a partir de 2008, as quais insistem em escrever um referencial teórico-prático não-todo, proponho a seguinte síntese, cujos momentos podem ser descritos com os seguintes tempos lógicos: 1.:: os espaços descontínuos dos discursos concretos são atravessados pelas determinações inconscientes, portanto, a partir da metapsicologia freudiana, a noção de que um aparelho psíquico cede lugar a um aparelho de linguagem, que permite pensar a aquisição da escrita pela criança como um processo de subjetivação; $2 .{ }^{\circ}$ : a realidade passa a ser pensada a partir da inclusão do sujeito na experiência, isto é, em sua estrutura de fantasia, pois não existe outra realidade senão aquela com que um sujeito se implica; 3.0 : o móvel principal da escrita é a impossibilidade de serem complementares as relações entre sujeito e objeto, ou seja, o conceito de letra nos ensina sobre a renúncia ao puro gozo e sobre a separação do autoerotismo, responsáveis pela entrada do sujeito na dialética do Outro.

\section{CONSIDERAÇÕES FINAIS}

Considerar a concepção de corpolinguagem delineada acima permite pensar os termos "linguagem", "ensino"e "subjetividade" em seu enodamento irredutível, ou seja, o modo como eles se põem em relação não possibilita pensá-los isoladamente, mas sim exige que ao se pensar um campo já se esteja invadindo os dois outros. Linguagem é condição de sujeito, ensino é linguagem, sujeito é corpo pulsional que só se articula como linguagem. Discutir, portanto, os três elementos principais envolvidos na trama educativa, criança, professor e texto, exige considerar que estamos diante de um processo que se dá para além da dualidade aluno-professor, ou seja, considerar que o texto possa exercer aí a função do terceiro elemento. Do mesmo modo que, na relação mãe-criança, a função paterna é condição para a constituição de um corpo pulsional, pode-se pensar que, na relação aluno-professor, o texto, o encadeamento de significantes, funciona ao mesmo tempo como um apoio e um deslocamento do saber.

Vale dizer que, na escola, o professor se autoriza diante de seus alunos sobretudo porque ele se coloca também na dependência do Outro, ou seja, da história fincada pelos discursos que o antecedem. No entanto, isso não impede o processo de se deslocar, incessantemente, pois nesse processo o sujeito é convocado a situar-se de modo singular diante do que lhe é ofertado 
e demandado. Dá-se aí uma escolha inconsciente desse sujeito, um estilo, um modo único de oferecer seu corpo no lugar da falta que esse Outro comporta.

O "em torno da letra", que comparece neste artigo, desde o título, realça o argumento de que, no percurso rumo à "aquisição" da escrita, o texto, que não é um objeto como os demais, põe-se ali no meio, entre a criança e o professor, como uma pauta musical, que impõe limites e permite brechas de liberdade, como um simbólico recortado de falhas que convocam o real, como uma instância cavada no embate entre o eu e o Outro. É nessa instância, nessa esfera legal com faltas constitutivas, que o professor atua. Portanto, mais do que ensinar, a sua função é endereçar à criança o seu desejo, desejo do Outro, desejo de que ela deseje aprender. Para essa função, há, no entanto, um limite, e é imprescindível que este entre na conta: de nada adiantarão suas demonstrações, suas exigências, suas correções, seus encadeamentos discursivos, se esses não forem tomados como questões pelo próprio sujeito, que, embora tenha como única opção dirigir-se a um saber que vem do Outro, só poderá deslanchar se o tomar como percurso singular. Algo lhe é demandado, mas essa demanda tem que ser subjetivamente interpretada. Aí sim haverá a possibilidade de advir um estilo, isto é, a marca do sujeito no texto.

\section{ABOUT LETTERS: LANGUAGE, TEACHING AND SUBJECTIVITY}

ABSTRACT: This article is a continuation of an investigation, a follow up on previous research around the theme of language, psychoanalysis and education, about what is at stake when one proposes to consider a child's first attempts at language. Considering more specifically the process of school literacy, I will try to discuss the function of text as well as the desiring game that its materiality could constitute, which approaches the unconscious process in which subjectivity can be situated. Firstly, I will consider certain issues, introduced by Borges (2006), on the literacy process and the role of text. Secondly, I will treat the implications of the fundamental concepts of psychoanalysis, in order to discuss the question of subjectivity. Finally, I will take the three irreducibly intertwined items of the title, language, teaching and subjectivity, which will allow me to discuss the three main elements involved in the educational process - child, teacher and text.

KEYWORDS: Role of text. Writing. Body language.

\section{NOTAS}

1. Superfície que Lacan toma emprestada da topologia para discutir o processo de causação do sujeito como divisível. Conforme Kaufmann (1996), se refendermos 
a banda de Moebius pelo meio, essa operação não engendra duas novas bandas semelhantes, mas apenas uma, não semelhante.

2. A autora recorre aqui a Jacques Derrida (1973), em sua Gramatologia.

3. Conforme Roudinesco e Plon (1998, p. 511), atentando-se ao que diz Freud, em 1915 - "proponho falar de apresentação metapsicológica quando logramos descrever um processo psíquico em suas relações dinâmica, tópica e econômica"--, seria preciso agrupar sob o rótulo de metapsicologia uma grande parte da obra freudiana. $\mathrm{Na}$ elaboração de Borges (2006), ressaltam-se, entre outras: A interpretação das afasias; Projeto para uma psicologia científica; o sétimo capítulo de $A$ interpretação dos sonhos; a "Carta 52" e "O bloco mágico".

4. Conforme Kaufmann (1996), o ponto em que o vivo pactua com a linguagem.

5. Algumas palavras que talvez possam ajudar o leitor quanto ao conceito de Outro: tanto no decorrer de nossas pesquisas quanto no percurso deste texto, o termo "Outro" vai-se matizando com diversas, mas não excludentes, noções, e isso tem a ver com o modo como Lacan, em sua obra, caminha com essa abordagem. Primeiramente, pode ser entendido como linguagem, ou, como diz Mota (1995), "funcionamento linguístico discursivo"; depois, pode estar referindo-se à imagem, isto é ao /deal de Eu, construída no jogo dissimétrico instituído entre o emissor e o receptor da mensagem; por fim, ele seria resto inassimilável da relação/não relação entre um falante e outro, ou ainda entre o Eu e o seu próprio corpo. Realce: esse Outro, em todos esses casos, diz respeito à divisão do Eu.

\section{REFERÊNCIAS BIBLIOGRÁFICAS}

ALLOUCH, J. Letra a letra: transcrever, traduzir, transliterar. Rio de Janeiro: Campo Matêmico, 1995.

BERGÈS, J. Do corpo à letra. [Transcrição de uma conferência em Poitiers, em $10^{\circ}$ de outubro de 1994, por convite do C. M. P. P. de la Vienne - Tradução provisória de Ângela Vorcaro]. 1994.

BORGES, S. O quebra-cabeça: a alfabetização depois de Lacan. Goiânia: Editora da UCG, 2006.

BURGARELLI, C. G. Linguagem e escrita: por uma concepção que inclua o corpo. Goiânia: Editora da UCG, 2005.

. Escrita e corpo pulsional. Tese (Doutorado em Linguística) - Instituto de Estudos da Linguagem, Unicamp, Campinas, SP, 2003.

CARVALHO, M. A. S. Escrita, repetição e elaboração. Tese (Doutorado em Educação) Faculdade de Educação da Universidade Federal de Goiás, Goiânia, 2011.

COSTA, A. Corpo e escrita: relações entre memória e transmissão da experiência. Rio de Janeiro: Relume Dumará, 2001. 
DERRIDA, J. Gramatologia. São Paulo: Perspectiva, 1973.

JAKOBSON, R. Linguística e comunicação. São Paulo: Cultrix, 1988.

KAUFMANN, P. Dicionário enciclopédico de psicanálise: o legado de Freud e Lacan. Rio de Janeiro: Jorge Zahar, 1996.

LACAN, J. L'Identification. Seminário inédito. [Divulgação provisória da Associação Freudiana Internacional]. 1961 e 1962.

A instância da letra no inconsciente ou a razão desde Freud. In: Escritos. Rio de Janeiro: Jorge Zahar, 1998.

. O seminário, livro 4: a relação de objeto. Rio de Janeiro: Jorge Zahar, 1995.

MOTA, S. B. V. O quebra-cabeça : a instância da letra na aquisição da escrita. Tese (Doutorado em Psicologia da Educação) - Pontifícia Universidade Católica de São Paulo, São Paulo, 1995.

.et al. Projeto escrita: ressignificando a produção de textos. Projeto de pesquisa UFG/CNPq, 1996. (Mimeo).

ROUDINESCO, E.; PLON, M. Dicionário de psicanálise. Rio de Janeiro: Jorge Zahar, 1998.

Cristóvão Giovani Burgarell é Professor da Universidade Federal de Goiás. Editor da revista Inter-Ação. Pesquisador nos projetos "Em torno da letra: escrita, leitura e transmissão" (UFG) e SEMASOMa (IEL/ Unicamp). É psicanalista, membro do Espaço Psicanalítico de Goiânia.

E-mail: crgiovani@gmail.com 